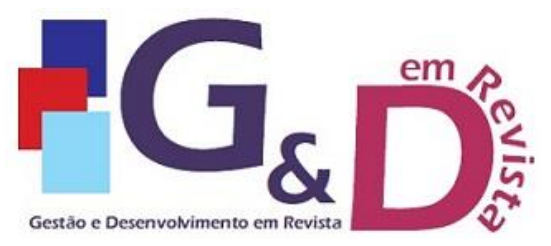

\title{
ANÁLISE DA PERCEPÇÃO DOS RESIDENTES SOBRE O DESENVOLVIMENTO TURÍSTICO DE CANGUARETAMA
}

\author{
Cleisson Ailton Silva \\ Técnico Subsequente em Manutenção e Suporte em Informática pelo Instituto Federal de Educação, \\ Ciência e Tecnologia do Rio Grande do Norte - IFRN. \\ E-mail: cleissondemathus@gmail.com
}

\author{
Alice Barros da Silva \\ Doutor em Demografia pela Universidade Estadual de Campinas - UNICAMP. Atualmente é \\ professoa associada da Universidade Estadual do Oeste do Paraná - UNIOESTE. \\ E-mail: alicebarros@outlook.com
}

\section{Márcio Marreiro Chagas}

Graduação em Turismo. Mestrado em Turismo. Doutorado em Administração. Atualmente é professor do Instituto Federal de Educação, Ciência e Tecnologia do Rio Grande do Norte (IFRN - Campus

Canguaretama).

E-mail:marcio_marreiro@yahoo.com.br

\section{RESUMO}

O estudo pretende analisar as percepções dos residentes sobre o desenvolvimento turístico e interação entre residentes e turistas em Canguaretama/RN. A pesquisa se caracteriza como descritiva, de natureza quantitativa, tipo survey, de corte transversal. A amostra foi realizada de modo não probabilístico e o sujeito escolhido pelo método por conveniência. A coleta de dados foi feita por meio de formulário, com afirmações em uma escala métrica de 11 pontos, obtendo um total de 126 formulários válidos. Os dados coletados foram analisados utilizando-se de estatísticas descritivas através do software Statistical Package for Social Science (SPSS 22.0). Dentre os resultados foi observado que os residentes têm elevadas percepções sobre os impactos positivos e baixas percepções no que diz respeito ao impactos negativos, moderado apego a comunidade, elevada percepção sobre os benefícios pessoais, baixa interação com os visitantes e emoções neutras durante a interação e apoio ao desenvolvimento turístico.

Palavras-chave: Percepção do residente. Desenvolvimento sustentável. Nível de interação. Emoções sentidas durante a interação.

\begin{abstract}
The aim of this paper is to analyze the perceptions of residents about the tourism development and the interaction between residents and tourists in Canguaretama/RN. Was realized a descriptive research using a quantitative analytical approach, survey type, cross-sectional. The sample was carried out in a non-probabilistic manner and the subject was chosen by the convenience method. To collect data, the instrument was a form, with statements on an 11 point metric scale, obtaining a total of 126 valid forms. The collected data were analyzed using descriptive statistics through the software Statistical Package for Social Science (SPSS 22.0). Among the results, it was observed that residents have high perceptions about positive impacts and low perceptions with regard to negative impacts, moderate attachment to the community, high perception of personal benefits, low interaction with visitors, neutral emotions during the interaction with tourists and support tourism development.
\end{abstract}

key-words: Resident's perception. Sustainable development. Interaction level. Emotions felt during the interaction. 


\section{INTRODUÇÃO}

Diversos estudos definem o turismo como uma das atividades que mais geram benefícios econômicos nos destinos indutores, principalmente onde é possível vivenciar o turismo de sol e praia (CHAGAS, 2014). O fluxo de viajantes impacta os destinos, beneficiando outros setores econômicos e alterando significativamente o meio ambiente, a sociedade e a cultura dos locais visitados. A participação e envolvimento da comunidade local é característica intrínseca do turismo e demanda a inclusão deste stakeholder em todas as fases do planejamento e execução das práticas turísticas a fim de alcançar a sustentabilidade, pois a comunidade que é integrada e beneficiada com a exploração turística tende a ter maior empatia e aceitação da atividade (BRANDÃO; BARBIERI; JUNIOR, 2013; TONON; CARDOZO, 2013; VIEIRA, 2014).

Barreto (2004) considera que apenas uma parcela da população tem contato direto com os turistas, em lugares diversos e de maneira formal ou informal. Tal interação pode estar diretamente relacionada ao apoio desses residentes e deve ser um dos fatores analisados para o estudo da percepção de uma comunidade sobre a atividade turística. É fundamental identificar a percepção da comunidade sobre o desenvolvimento do turismo e conhecer a população local para que sejapossível trabalhar em melhorias e um desenvolvimento sustentável (PEREIRA, 2017).

Ao se considerar quais emoções são despertadas durante 0 contato entre turista e residente, busca-se compreender como as emoções podem ser positivas para ambas as partes (RODRIGUES, 2012). Diante desta perspectiva faz-se necessário desenvolver estratégias que façam com que o residente se sinta mais confortável com essa interação, preservando o seu lugar de origem, sua identidade cultural e se adaptando às mudanças ocasionadas pelo turismo (BENI, 2002). É relevante observar o nível de interação e como esta influencia a percepção do residente sobre o desenvolvimento turístico em uma localidade. Ao se considerar participante e reconhecer os ganhos advindos, o residente se torna mais favorável a atividade (XU et al, 2016). Com base nesta perspectiva, pressupõe-se que uma parcela da população que apoia o desenvolvimento da atividade tem uma maior interação com o turista, ao contrário das que não apoiam.

Sob esse prisma, esta pesquisa objetiva identificar qual a percepção da comunidade local sobre o turismo considerando as dimensões do desenvolvimento da atividade, apego a localidade, benefícios pessoais, a interação entre turistas e residentes, e as emoções despertadas. A comunidade estudada é da cidade de Canguaretama, Estado do Rio Grande do Norte, Brasil, situada a 85 quilômetros de Natal, capital do estado.

\section{REFERENCIAL TEÓRICO}

\subsection{DESENVOLVIMENTO SUSTENTÁVEL DO TURISMO E A PARTICIPAÇÃO DOS AUTÓCTONES}

O desenvolvimento sustentável é considerado uma melhoria no modo de vida humano, preservando os recursos naturais e a integridade humana. De acordo com Esteves (2005), a sustentabilidade funciona como um sistema de manutenção onde a sua duração irá depender do seu grau de adaptação à diversidade, resiliência, equidade do sistema e interação entre as diferentes dimensões 
ambiental, social, cultural e econômica. Sob essa ótica, o turismo deve ser visto como um sistema que integra diversos âmbitos da comunidade, cuja participação é indispensável para que se possa afirmar que de fato aquele local se encaixa nos padrões de sustentabilidade (GARROD; FYALL, 1998; BRANDÃO; ET AL, 2013; RODRIGUES 2012; VIEIRA, 2014).

O apoio da população local é fundamental para que tal desenvolvimento turístico seja válido, desta forma torna-se vital que todos os planejadores da atividade turística tenham noção da importância da voz que a comunidade local tem, pois assim conflitos entre visitantes e autóctones podem ser minimizados. Valorizar a comunidade como um agente desenvolvedor de produtos e serviços turísticos com participação ativa é vista como uma das alternativas que possam envolver e garantir o apoio da população local, além de gerar benefícios para todos os envolvidos (SCALABRINI, 2014).

Sendo assim torna-se relevante compreender que a inter-relação entre comunidade e visitantes é vista como um fator primordial para a manutenção da atividade turística, devido ao fato de que dentro de uma sociedade existem diferentes grupos de interesse e que quando tais grupos divergem sobre determinados assuntos maiores problemas podem surgir, desta forma torna-se necessário que o planejamento seja feito visando garantir o bem estar de todos para que assim os possíveis problemas sejam sanados.

\subsection{CONCEITOS E CARACTERÍSTICAS DAS DIMENSÕES}

\subsubsection{Apego ao lugar}

O apego é definido como um forte sentimento de pertencimento ou ligação de uma ou mais pessoas a sua localidade, diversos autores estudam o apego a fim de explicar e entender o comportamento humano (HIDALGO; HERNÁNDEZ, 2001; FUNK; JAMES, 2006; GURSOY; RUTHERFORD, 2004; JUROWSKI et al, 1997; GURSOY et al 2002). De acordo com Woosnam e Aleshinloye (2015), o apego ao lugar pode refletir diretamente na participação de um indivíduo dentro de sua comunidade, fazendo com que esta mesma pessoa passe a ter uma ligação emocional com o lugar.

O apego ao lugar é um vínculo no qual as pessoas se conectam a lugares ou outras pessoas, fazendo que assim sintam que pertencem a este lugar e crie laços afetivos e emocionais (SILVA E CHAGAS, 2018). Um dos motivadores do apego está ligado ao lugar onde determinada pessoa escolhe morar, ou seja, diversos atributos daquele local podem influenciar o sentimento de pertencimento de um residente, seja ele social ou até mesmo devido aos atrativos e a própria localização (LIMA; BOMFIM, 2009), como também é perceptível uma relação diretamente proporcional entre apego e o tempo que uma pessoa vive em uma determinada comunidade (SILVA E CHAGAS, 2018).

$\mathrm{O}$ apego pode ser definido como um meio pelo qual os indivíduos sentem-se ligados a sua comunidade através da obtenção de benefícios advindos de uma determinada atividade geradora de renda (GURSOY; RUTHERFORD, 2004; JUROWSKI et al, 1997; GURSOY et al 2002; BOLEY et al, 2014), ou relacionado ao simbolismo de que as raízes do lugar se projetam através das memórias criando assim o sentimento de pertencimento (WILLIAMS et al, 1992) e ainda pode ser uma série de significados que uma determinada localidade tem sobre o indivíduo, além 


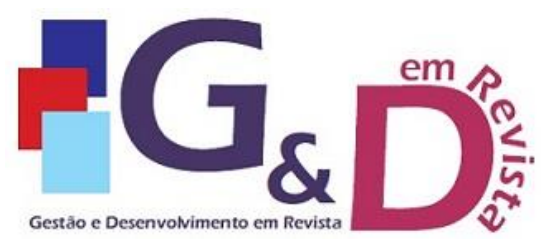

Gestão e Desenvolvimento em Revista V. 8, N. 2, jul-dez/2021, p. 153-169.

ISSN online: $2446-8738$

Artigo recebido em: 11/02/2021

Artigo aprovado em: 08/09/2021

de conhecimentos, comprometimento e satisfação (WANG; CHEN, 2015).

\subsubsection{Impactos percebidos do turismo}

De acordo com a literatura os impactos do turismo podem ser vistos a partir de diferentes perspectivas, que são elas: econômicas, sociais, ambientais e culturais, sendo cada um desses impactos específicos de cada comunidade a partir do seu nível de desenvolvimento turístico (ANDERECK; et al., 2005; CHAGAS; et al., 2016; SILVA, 2018; MORALES; et al., 2018). Os impactos negativos do turismo podem ser relacionados a fatores ambientais tais como poluição, sujeira, depredação ambiental, destruição da natureza e o desmatamento; sociais com problemas relacionados à violência, prostituição, tráfico de drogas, congestionamento de tráfego, superlotação em locais públicos entre outros (ANDERECK; et al., 2005; CHAGAS; et al., 2016; ALMEIDA GARCIA; et al., 2016; WILLIANS; LAWSON, 2001). Problemas econômicos como aumento no preço dos produtos e serviços, dependência econômica do setor, sazonalidade dos trabalhos, vazamento de receita turística, aumento de imposto de propriedades (HARALAMBOPOULOS; PIZAM, 1996; CHAGAS, 2014; CHAGAS; et al., 2016; SILVA, 2018) e culturais onde é possível analisar impactos negativos relacionados a perda de identidade cultural, destruição do patrimônio histórico cultural, descaracterização do artesanato local, arrogância cultural (AP; CROMPTON, 1998; HALLAL; MÜLLER, 2013, BARRETO, 2009).

Já no que diz respeito aos impactos positivos do turismo é apresentado como fatores ambientais o estímulo à preservação ao meio ambiente, investimento em infraestruturas ambientais, contato com a natureza, limpeza dos patrimônios e atrativos, conscientização ambiental e educação em relação ao meio ambiente (ANDERECK; NYAUPANE 2011; ANDERECK; et al., 2005; BRUNT; COURTNEY, 1999), já os sociais podem ser vistos como intercâmbio social e cultural, melhoria na qualidade de vida, melhoria na infraestrutura turística e urbana, mais opções de lazer ao ar livre e melhoria em prestação de serviços públicos (SON; PIGRAM; RUGENDYKE 2002; BRUNT; COURTNEY 1999; MORALES; et al., 2018), No que se refere aos econômicos é possível citar aumento nas oportunidades de emprego, desenvolvimento econômico, investimento na economia local e aumento da renda da população (CHAGAS, 2014; MORALES; et al., 2018; GUO; et al., 2017; COSTA; MARES, 2016; BUJOSA; ROSELLÓ, 2007), os culturais podem ser vistos como resgate da cultura local, preservação cultural, interação com diferentes culturas e valorização do artesanato local (BRANDÃO; BARBIERI; JUNIOR, 2013; HALLAL; MÜLLER, 2013; MORALES; ET AL, 2018; AP; CROMPTON, 1998).

Para Hallal e Müller (2013), os impactos positivos ou negativos estão relacionados à percepção que a comunidade tem sobre quais são as vantagens e desvantagens do turismo sobre as questões ambientais, sociais, culturais e econômicas. É evidente que os impactos do turismo são inerentes às transformações ocorridas durante um processo de desenvolvimento turístico em comunidades que recebem um determinado fluxo de visitantes. Além disso, o frequente contato do turista tanto com os residentes quanto com o seu entorno acaba impactando o ambiente de forma significativa.

\subsubsection{Interação entre residentes e turistas}


A interação entre residentes e turistas é inerente ao turismo e capaz de modificar a percepção de ambos sobre a prática da atividade turística, minimizar o preconceito existente entre eles e reduzir as atitudes negativas dos residentes em relação aos turistas (RODRIGUES, 2012; WARD; BERNO, 2011). Ressalta-se que essa interação possui um amplo espectro com variações nos graus de contato entre visitante e visitados, desde o contato estritamente formal com os prestadores de serviços turísticos até 0 que visitantes estabelecem quando se inserem informalmente nas comunidades receptoras transitando nas ruas, interagindo em atividades recreativas e desportivas e durante tarefas corriqueiras dos residentes (BARRETO, 2004; RODRIGUES, 2012; AIRES; PEQUENO; FORTES 2010, JOO et al, 2018).

Entretanto quando este contato é menos frequente pode ocorrer um desconhecimento por parte do residente sobre o desenvolvimento do turismo e a falta de conhecimento dos turistas sobre a comunidade visitada, posicionando a comunidade como mais um atrativo a ser observado sem uma interação real entre as partes. Quando não ocorre uma interação que possibilite uma troca cultural rica e interessante entre turistas e residentes, exclui-se da experiência turística uma característica essencial, reduzindo a prática apenas a uma relação apenas de interesse econômico, pois de uma forma ou de outra o turista gera economia na localidade que visita (DIAS, 2005; KRIPPENDORF 2009; BARRETO, 2009).

\subsubsection{Emoções dos residentes sentidas durante a interação}

A emoção pode ser descrita como um processo no qual o indivíduo experimenta sensações no corpo que são desencadeadas devido a imagens mentais que estimulam um sistema cerebral específico (DAMÁSIO, 1996), induzindo o indivíduo a verificar se algo é bom ou ruim, podendo determinar seu comportamento (RODRIGUES, 2012). A emoção é o resultado de diferentes problemas e mudanças, que geralmente facilita o processo de tomada de decisão preparando o indivíduo para respostas mais rápidas e fornecendo contínuas informações sobre a cíclica troca entre organismo e meio-ambiente (GROS, 1998).

A perspectiva das emoções relacionadas ao turismo, é objeto de estudo de diversos autores que adotam escalas para mensurar as emoções sentidas, tais como a Pleasure Arouse Dominace (PAD) de Mehrabian \& Russell (1974), a Positive Affect Negative Affect Scale (PANAS) de Watson et al. (1988) e a Consumption Emotions Set (CES) de Richins (1997). As emoções que são despertadas através do contato entre autóctone e visitante são reflexos do nível de interação existente entre eles, onde o residente pode demonstrar de diferentes maneiras os seus sentimentos acerca da presença de turistas. No trabalho de Woosnam e Aleshinloye (2015), a emoção é trabalhada a partir da solidariedade emocional onde os residentes e turistas tem uma noção do "nós" ao invés do "eu versus você", identificando assim o grau de proximidade entre eles e as emoções despertadas durante o contato. De acordo com Ribeiro et al (2018), a solidariedade emocional existente entre autóctones e visitantes é um fator primordial para o sucesso de um destino turístico.

Para Barreto (2009), as emoções estão ligadas a como a comunidade vê o turista e o desenvolvimento da atividade na região, pois em determinado ponto da atividade a hostilidade dos residentes em relação ao turista vai aumentando cada vez mais, acarretando problemas que podem dificultar o funcionamento da atividade. É necessário que o sentimento dos autóctones seja levado em consideração para 
que não haja conflitos e hostilidade que possam espantar os visitantes e comprometer o bem-estar dos residentes.

Acerca disso, é possível notar que o sentimento do residente segue um padrão de acordo com o nível de desenvolvimento turístico da comunidade, que é definido através da escala de relação que foi apontada por Doxey (1975), onde é mostrado a irritabilidade da população em relação ao visitante. Os índices são pautados em quatro estágios que são: euforia, apatia, irritação e antagonismo. Para Aires e Fortes (2011), esta escala pode ter mais de uma atitude do residente em um mesmo período em um destino turístico, podendo assim o não seguimento das fases do modelo proposto por Doxey (1975) ser explicada por outros fatores.

\subsubsection{Benefícios pessoais}

É irrefutável que qualquer atividade que agregue vantagens econômicas para um indivíduo será vista de forma positiva. Estudos mostram que os ganhos econômicos da atividade turística podem melhorar as condições de vida da comunidade na qual o turismo está em desenvolvimento (BOLEY; STRZELECKA; WOOSNAM, 2018; YU; COLE; CHANCELLOR, 2018). Para Perdue et al (1990), os benefícios pessoais do desenvolvimento turístico se baseiam na percepção de que o residente pode obter vantagem econômica, adotando esta atividade como alternativa para incremento de renda, considerando uma prática positiva mediante o ganho destas vantagens pessoais significativas (MCGEHEE; ANDERECK, 2004).

Em contrapartida, Wang e Pfister (2008), analisam que os benefícios pessoais podem ser vistos de perspectivas além da econômica, considerando o ponto de vista social como a revitalização do centro da cidade, eventos e programas especiais e opções de compras e restaurantes. Xu et al (2016) afirma que os residentes não percebem os benefícios pessoais da atividade turística, mas sim os benefícios comunitários que possam agregar valor aos residentes.

A análise dos benefícios pessoais é algo bastante individual e relacionado com o modo como o turismo é experienciado por cada autóctone. De acordo com Boley et al (2014), a teoria de Weber mostra que o comportamento de um indivíduo pode ser classificado de duas formas, a racionalidade formal (ganhos econômicos) e a substantiva (aspectos não econômicos). O envolvimento do residente também influencia esta interpretação, já que a percepção positiva sobre os benefícios oriundos do desenvolvimento do turismo auxiliam a melhorar significativamente o padrão de vida dos residentes que se sentem empoderados e envolvidos com a atividade (LV; XIE; LI, 2019).

\section{METODOLOGIA DA PESQUISA}

\subsection{TIPOLOGIA DA PESQUISA}

Esta investigação se caracteriza como descritiva, de natureza quantitativa, além de ser do tipo survey de corte transversal. A amostra foi realizada de modo não probabilístico, com a escolha do sujeito realizada por meio de uma amostragem pelo método por conveniência. A população investigada foi constituída pelos residentes do município de Canguaretama, Estado do Rio Grande do Norte, Brasil, cuja praia de Barra de Cunhaú é um de seus principais atrativos naturais e fortemente reconhecida no mercado turístico. Está situada a 85 quilômetros de Natal, capital do 
estado, conta também com uma população estimada em 34.267 habitantes. Ocupando uma área total de 245,408 km² (IBGE, 2018).

A coleta de dados foi feita através de formulários, com afirmações em uma escala métrica de 11 pontos, em que 0 indica total discordância e 10 total concordância. Os dados foram coletados nos períodos entre 10/02/2018 até 30/04/2018, obtendo um total de 126 formulários válidos.

Em relação ao número de variáveis foram no total de 41, divididas em (07) dimensões: impactos positivos (06 questões), impactos negativos (07 questões), apoio do residente ao desenvolvimento do turismo (06 questões), interação entre residente e visitante (06 questões), apego (04 questões), benefícios pessoais (04 questões), emoções sentidas durante a interação (08 questões). Ao final foi analisado questões relacionadas ao perfil socioeconômico do residente, contendo informações relativas à gênero, estado civil, se trabalha ou não com o turismo, tempo que vive na comunidade, idade, escolaridade, renda familiar mensal em reais e bairro de residência.

As variáveis utilizadas referentes aos impactos do turismo foram baseadas em Perdue, Long e Allen (1990), Silva, Chagas e Marques Junior (2016), Silva e chagas (2016), Chagas (2014), Rodrigues (2012), Brandão, Barbiere e Junior (2013), Rodrigues et al. (2014), Chagas et al. (2016), Pereira (2017), enquanto as dimensões de apego ao lugar foram adaptadas do estudo de Gursoy e Rutherford (2004), Chagas, Silva e Marques Junior (2016), Silva e Chagas (2016), Rodrigues (2012), Hidalgo e Hernández (2001), Santoro (2014), Rodrigues et al. (2014), Chagas et al. (2016), Rollero e Piccoli (2010), Willians, Patterson e Roggenbuck (1992). Já a dimensão interação entre residente e visitante e a dimensão de emoções sentidas durante a interação foi baseado em Aires, Pequeno e Fortes (2010), Rodrigues (2012), Barreto (2004), Zacarias (2014), Joo et al (2018), Woosnam et al (2018), Woosnam e Norman (2010), Ribeiro et al (2018). Os benefícios pessoais foram baseados em Perdue, Long, Allen (1990), Ribeiro et al. (2017), Boley et al. (2014), Maragh, Gursoy e Vieregge (2015), Xu et al (2016). E, por fim, a dimensão relacionada ao apoio do residente foi baseada em Nunkoo e Ramkissoon (2011), Silva, Chagas e Marques Junior (2016), Silva e Chagas (2016), Rodrigues (2012), Rodrigues et al., (2014), Vieira (2014), Chagas et al. (2016), Silva (2014), Santos (2014) e Pereira (2017).

Os dados coletados por meio dos formulários foram inseridos no software Statistical Package for Social Science (SPSS 22.0). Por meio do qual ocorreu a análise dos dados utilizando-se de estatísticas descritivas.

\section{DISCUSSÃO DOS RESULTADOS}

\subsection{PERFIL DA AMOSTRA}

A amostra foi composta majoritariamente pelo gênero masculino apresentando o percentual de $56,3 \%$ e o feminino, $43,7 \%$. Em relação ao estado civil foi identificada a predominância dos solteiros $(59,5 \%)$, casados $(25,4 \%)$, divorciados $(5,6 \%)$ e outros $(9,5 \%)$. O nível de escolaridade predominante foi ensino médio $(46,8 \%)$, seguido pelo ensino superior $(26,2 \%)$, ensino fundamental $(21,4 \%)$, pósgraduação $(3,4 \%)$ e sem instrução formal $(2,4 \%)$. A faixa etária com maior representatividade da amostra foi entre 18 a 25 anos (38,4\%), 36 a 50 anos (24\%), 26 a 35 anos (18,4\%), 51 a 65 anos (10,4\%), 14 a 17 anos (6,4\%) e acima de 65 
anos $(2,4 \%)$.

A maior parcela dos entrevistados tem renda familiar entre $R \$ 938,00$ e $R \$$ $1.876,00$ (46,6\%), em sequência até $R \$ 937,00(29,6 \%), R \$ 1.877,00$ a $3.752,00$ $(20,8 \%)$ e de $R \$ 3.753,00$ a $R \$ 7.504,00$ (4\%). A menor proporção da amostra trabalha com turismo (12,7\%) e $87,3 \%$ dos residentes não trabalham com o setor. Em relação ao tempo em que os residentes vivem na comunidade, a maioria reside de 8 a 20 anos (39,7\%) acompanhado pelos que vivem de 21 a 30 anos (26,2\%), acima de 30 anos (24,6\%), 1 a 7 anos (7,9\%) e com menos de 1 ano de residência $(1,6 \%)$. Os respondentes residem em sua maioria no bairro Areia Branca $(26,2 \%)$ seguido do Centro (23,9\%), Sertãozinho (17,5\%), Barra do Cunhaú $(7,1 \%)$, Piquiri (6,3\%), Lagoa de São João e Projeto Crescer 4,8\% cada bairro, Jiqui e Catu 3,2\% cada bairro, Estação (1,6\%), Jiqui Campo (0,8\%) e Salem (0,7\%).

\subsection{PERCEPÇÃO DOS RESIDENTES SOBRE O DESENVOLVIMENTO TURÍSTICOS}

A percepção dos residentes sobre os impactos positivos do turismo foram avaliados pelos respondentes através de 6 variáveis, conforme exposto na tabela 01 . É possível aferir que os residentes acreditam que a atividade turística pode impactar a comunidade de forma positiva. Essa afirmação é corroborada pela média das variáveis desta dimensão, que variam entre 7,71 e 8,34. Destacando-se a variável "Eu acredito que o aumento do turismo na cidade poderá estimular a valorização da cultura local" com a maior média da dimensão analisada $(8,34)$.

Tabela 01: Percepção dos residentes sobre os impactos positivos do turismo

\begin{tabular}{|l|c|c|}
\hline \multicolumn{2}{|c|}{\begin{tabular}{c} 
Variáveis \\
\multicolumn{2}{|c|}{}
\end{tabular}} & \multicolumn{2}{c|}{ Média } & $\begin{array}{c}\text { Desvio } \\
\text { padrão }\end{array}$ \\
\hline Eu acredito que o aumento do turismo na cidade... & 7,89 & 2,26 \\
\hline poderá aumentar a renda para as pessoas que moram aqui & 8,29 & 1,999 \\
\hline poderá melhorar o emprego para as pessoas que moram aqui & 7,71 & 2,098 \\
\hline poderá melhorar a qualidade de vida das pessoas que moram aqui & 8,03 & 2,169 \\
\hline poderá melhorar a infraestrutura da cidade & 7,83 & 2,27 \\
\hline poderá estimular a preservação ambiental & 8,34 & 2,075 \\
\hline poderá estimular a valorização da cultura local & &
\end{tabular}

Fonte: Dados do estudo, 2018.

Os impactos negativos advindos com o desenvolvimento do turismo também foram avaliados pelos residentes, através de 7 variáveis, apresentadas na tabela 02 . Embora a média das variáveis demonstrem que os residentes não acreditam que o desenvolvimento da atividade turística possa trazer impactos negativos, a variável relacionada ao aumento do preço de produtos e serviços na comunidade tem uma avaliação destoante. Os residentes acreditam em tal afirmação. A variável acerca de perda da qualidade de vida com o aumento do turismo, com média 3,03 corrobora o resultado da dimensão de impactos positivos expostos na tabela 01 , onde foi visto 
que os residentes acreditam que o turismo é capaz de melhorar sua qualidade de vida $(7,71)$.

Tabela 02: Percepção dos residentes sobre os impactos negativos do turismo

\begin{tabular}{|c|c|c|}
\hline $\begin{array}{c}\% \\
\text { Variáveis }\end{array}$ & Média & $\begin{array}{l}\text { Desvio } \\
\text { padrão }\end{array}$ \\
\hline \multicolumn{3}{|l|}{ Eu acredito que o aumento do turismo na cidade... } \\
\hline poderá aumentar a violência & 3,9 & 3,101 \\
\hline poderá aumentar a poluição ambiental & 4,67 & 3,159 \\
\hline poderá aumentar o crescimento desordenado da cidade & 4,68 & 3,006 \\
\hline poderá trazer perda da qualidade de vida & 3,03 & 2,662 \\
\hline poderá trazer aumento dos conflitos entre os moradores & 3,28 & 2,897 \\
\hline poderá afetar negativamente o modo de vida da população local & 3,15 & 3,002 \\
\hline poderá aumentar os precos dos produtos e serviços na cidade & 6,64 & 3,179 \\
\hline
\end{tabular}

Fonte: Dados do estudo, 2018.

Para análise do construto de apego ao lugar foram inseridas quatro variáveis, presentes na tabela 03. Os resultados expõem que os residentes têm um moderado apego a sua comunidade. $O$ desvio padrão das variáveis se mostraram elevados, o que corrobora para a dispersão dos resultados e médias menores e com valores abaixo de 7,00. Esta dispersão implica na existência de uma parcela da população que não sente um nível elevado de apego ao lugar, embora atribuam um significado muito importante a viver na cidade $(6,99)$.

Tabela 03: Percepção dos residentes sobre o apego a comunidade

\begin{tabular}{|l|c|c|}
\hline \multicolumn{1}{|c|}{$\begin{array}{c}\text { Variáveis } \\
\text { Eu prefiro viver nessa cidade do que em qualquer outra }\end{array}$} & Média & $\begin{array}{c}\text { Desvio } \\
\text { padrão }\end{array}$ \\
\hline Viver nessa cidade diz muito sobre quem eu sou & 6,58 & 3,196 \\
\hline Viver nessa cidade significa muito para mim & 6,75 & 2,805 \\
\hline Eu sou muito apegado a essa cidade & 6,99 & 2,761 \\
\hline
\end{tabular}

Fonte: Dados do estudo, 2018.

A dimensão acerca dos benefícios pessoais são apresentados na tabela 04 avaliada através de quatro variáveis. Os resultados apontam que a maioria significativa dos avaliados tem uma forte percepção sobre os benefícios pessoais do turismo, principalmente no que diz respeito aos benefícios que possam trazer melhoria de vida $(7,90)$ em contrapartida, a variável "Eu me sinto pessoalmente beneficiado pelo turismo na cidade" tem a menor média $(4,65)$. Tais resultados indicam que o turismo é visto como uma atividade importante e promissora, mas que ainda não gera benefícios significativos para os residentes. 


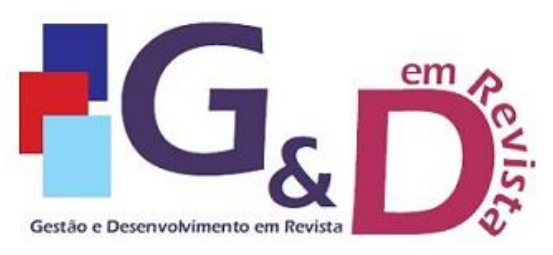

Gestão e Desenvolvimento em Revista V. 8, N. 2, jul-dez/2021, p. 153-169.

ISSN online: $2446-8738$

Artigo recebido em: 11/02/2021

Artigo aprovado em: 08/09/2021

Tabela 04: Percepção dos residentes sobre os benefícios pessoais

\begin{tabular}{|l|c|c|}
\hline \multicolumn{1}{|c|}{$\begin{array}{c}\text { Variáveis } \\
\text { Média }\end{array}$} & $\begin{array}{c}\text { Desvio } \\
\text { padrão }\end{array}$ \\
\hline Acho importante os benefícios do turismo que podem fazer eu melhorar de vida & 7,9 & 2,344 \\
\hline Acho importante os benefícios do turismo que podem me beneficiar diretamente & 7,36 & 2,588 \\
\hline Eu me sinto pessoalmente beneficiado pelo turismo na cidade & 4,65 & 3,428 \\
\hline Acredito que o turismo ajuda a melhorar minhas condições de vida & 6,32 & 3,11 \\
\hline
\end{tabular}

Fonte: Dados do estudo, 2018.

A tabela 05 mostra o nível de interação entre residentes e turistas, para a avaliação dos respondentes foram colocados um total de seis variáveis. A tabela mostra um baixo índice de interação de acordo com a média (entre 3,06 e 4,79), inferiores às demais médias deste estudo. Pode-se deduzir que há uma baixa interação entre os residentes e turistas na comunidade, corroborado pelo trabalho de Rodrigues (2012), que concluiu que não existe uma interação muito próxima entre residentes e turistas. O resultado por ser relacionado ao baixo envolvimento da comunidade no processo turístico e a pouca visitação de residentes nas áreas frequentadas por turistas. Entendimento reforçado pelos elevados níveis de desvio padrão, que apesar das médias baixas, mostra que existe uma parcela da população que afirma interagir com os turistas em determinados locais em sua comunidade, principalmente na interação onde os residentes tem contato com os turistas em atrativos.

Tabela 05: Percepção dos residentes sobre a interação entre residentes e turistas

\begin{tabular}{|l|c|c|}
\hline \multicolumn{1}{|c|}{$\begin{array}{c}\text { \% } \\
\text { Variáveis }\end{array}$} & Média & $\begin{array}{c}\text { Desvio } \\
\text { padrão }\end{array}$ \\
\hline Frequência de interação com turistas... & 3,06 & 3,319 \\
\hline no local de trabalho & 4,79 & 3,125 \\
\hline nos atrativos turísticos & 4,27 & 3,412 \\
\hline na rua (dando informações sobre locais aos visitantes) & 4,22 & 3,301 \\
\hline nos estabelecimentos comerciais & 4,13 & 3,306 \\
\hline em eventos & 3,33 & 3,398 \\
\hline em atividades recreativas ou esportivas & & \multicolumn{2}{l|}{} \\
\hline
\end{tabular}

Fonte: Dados do estudo, 2018.

$\mathrm{Na}$ dimensão de emoções sentidas durante a interação apresentada na tabela 06 foram analisadas um total de oito variáveis. Ressalta-se que uma parcela significativa dos entrevistados têm uma percepção neutra sobre as emoções durante o contato com os turistas, as médias variam de 5,57 a 6,96. Esta afirmação é reforçada pela variável "infeliz/feliz" que apresentou a maior média da dimensão $(6,96)$. Entretanto, duas médias se destacam no que diz respeito a menores valores de avaliação, são elas independente $(5,68)$, demonstrando que os residentes têm 
outras fontes de renda e não dependem significativamente do turismo. E a variável submisso $(5,57)$ que expõe a existência de sentimento de inferioridade dos residentes em relação aos turistas. Estes resultados podem ser atribuídos também à baixa interação existente entre as partes, como exposto na tabela 05 , o que faz com que os residentes estejam isentos em relação à emoção.

Resultados diferentes foram encontrados no estudo de Rodrigues (2012), onde foi identificado que as emoções despertadas através do contato entre residentes e visitantes são positivas. Além disso, a autora classifica tais emoções em "Arouse-Pleasure" e "Dominance" onde é mostrado que os residentes não se sentem dominados pela presença dos visitantes e sentem prazer em recebê-los.

Tabela 06: Percepção dos residentes sobre as emoções sentidas durante o contato entre residentes e turistas

\begin{tabular}{|l|c|c|}
\hline \multicolumn{1}{c|}{$\begin{array}{c}\text { \% } \\
\text { Variáveis }\end{array}$} & Média & $\begin{array}{c}\text { Desvio } \\
\text { padrão }\end{array}$ \\
\hline Infeliz/Feliz & 6,96 & 2,741 \\
\hline Desanimado/Animado & 6,7 & 2,846 \\
\hline Insatisfeito/Satisfeito & 6,54 & 2,81 \\
\hline Submisso/Dominante & 5,57 & 2,47 \\
\hline Desestimulado/Estimulado & 6,26 & 2,727 \\
\hline Aborrecido/Relaxado & 6,19 & 2,672 \\
\hline Desinteressado/Interessado & 6,69 & 2,864 \\
\hline Independente/Dependente & 5,68 & 2,561 \\
\hline
\end{tabular}

Fonte: Dados do estudo, 2018.

$\mathrm{Na}$ tabela 07 estão presentes as variáveis relacionadas à dimensão de apoio do residente ao desenvolvimento turístico, o número de variáveis exploradas foram seis. A tabela revela que o apoio do residente ao desenvolvimento turístico é elevado $(8,98)$. Este resultado pode estar relacionado ao fato de que a atividade turística na cidade ainda se encontra em fase de desenvolvimento, o que revela que os residentes se encontram em estado de euforia de acordo com a escala de Doxey (1990).

Apesar de acreditarem que o turismo é uma oportunidade para que a comunidade se desenvolva e gere benefícios e melhoria em seus padrões de vida, a menor média da dimensão é da variável "Eu prefiro que seja desenvolvido o turismo na cidade do que outras atividades econômicas da região, como a cana de açúcar e criação de camarão, por exemplo" $(6,27)$, cabendo a interpretação de que a maior parcela comunidade ainda não se sentiu beneficiada diretamente pelo turismo a ponto de o considerar uma atividade econômica viável, rentável e promissora. 


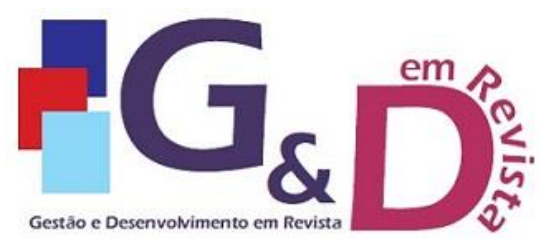

Gestão e Desenvolvimento em Revista V. 8, N. 2, jul-dez/2021, p. 153-169.

ISSN online: $2446-8738$

Artigo recebido em: 11/02/2021

Artigo aprovado em: 08/09/2021

Tabela 07: Percepção do residente sobre o apoio ao desenvolvimento turístico

\begin{tabular}{|l|c|c|}
\hline \multicolumn{1}{|c|}{$\begin{array}{c}\text { Variáveis } \\
\text { Eu apoio o desenvolvimento do turismo na cidade }\end{array}$} & Média & $\begin{array}{c}\text { Desvio } \\
\text { padrão }\end{array}$ \\
\hline Eu sou a favor do estímulo ao aumento do número de visitantes & 8,98 & 1,782 \\
\hline Acredito que o desenvolvimento do Turismo é muito importante para a cidade & 8,93 & 1,611 \\
\hline Eu acredito que a cidade deveria estimular mais o turismo & 8,87 & 1,597 \\
\hline Eu acredito que a cidade está melhor depois do turismo & 6,83 & 2,799 \\
\hline $\begin{array}{l}\text { Eu prefiro que seja desenvolvido o turismo na cidade do que outras atividades } \\
\text { econômicas da região, como a cana de açúcar e criação de camarão, por } \\
\text { exemplo. }\end{array}$ & & \\
\hline
\end{tabular}

Fonte: Dados do estudo, 2018.

\section{CONSIDERAÇÕES FINAIS}

Deste estudo, conclui-se que a percepção dos residentes sobre os impactos positivos do turismo é relativamente elevada, e que os respondentes não consideram o desenvolvimento da atividade como uma ameaça, exceto pela crença de que a atividade possa ocasionar o aumento no preço de produtos e serviços. Os residentes acreditam fortemente que o turismo pode gerar futuros benefícios pessoais, entretanto tais benefícios ainda não são uma realidade para a maioria da comunidade de Canguaretama, devido ao fato de que a cidade ainda está em fase de desenvolvimento turístico e não possui um fluxo tão intenso de visitantes.

O estudo expôs o baixo nível de interação entre turistas e residentes, mostrando que este contato é mais frequente nas áreas dos atrativos turísticos, que são pouco frequentadas pela comunidade local. Vale ressaltar que o destino que possui maior fluxo turístico entre os distritos de Canguaretama é Barra do Cunhaú, onde os empreendimentos visitados impossibilitam o contato direto com os residentes, exceto por aqueles que trabalham nestes locais, reduzindo a interação de turistas e comunidade local ao contato formal. As emoções despertadas durante estas interações foram consideradas neutras e os autóctones se consideram independentes dos visitantes.

Os resultados mostraram que os residentes apoiam o desenvolvimento da atividade turística, porém uma considerável parcela dos autóctones prefere que sejam desenvolvidas outras atividades econômicas em detrimento da atividade turística. A pesquisa mostrou também que os residentes possuem apego moderado à localidade, neste contexto é necessário o planejamento e execução de ações de fortalecimento cultural para elevar o senso de pertencimento dos residentes a comunidade.

Com base nos resultados, é fundamental que os gestores locais busquem realizar programas e projetos que incluam a comunidade no desenvolvimento do turismo, considerando outras atividades econômicas da região durante o planejamento, gerando cada vez mais impactos positivos, que sejam perceptíveis para a comunidade, assegurando que os preços dos serviços e produtos serão justos para residentes e visitantes, a fim de preservar a empatia e obter maior aceitação dos residentes ao desenvolvimento da atividade turística no destino. 


\section{REFERÊNCIAS}

AIRES, J. D. et al. A relação entre turistas estrangeiros e residentes: o caso de Ponta Negra-Natal/RN. Revista Hospitalidade, v. 7, n. 2, p. 38-51, dez. 2010.

ALMEIDA, F.; PELÁEZ, M.A.; BALBUENA, A.; CORTÉS, R. Residents' perceptions of tourism development in Benalmadena (Spain). Tourism Management. v. 54, p. 259-274, jun. 2016.

ANDERECK, Kathleen L. et al. Residents' perceptions of community tourism impacts. Annals of tourism research, v. 32, n. 4, p. 1056-1076, 2005.

AP, J.; CROMPTON, J. L. (1998). Developing and testing a tourism impact scale. Journal of travel research, v. 37, n. 2, p. 120-130, nov. 1998.

BARRETO, M. Cultura e turismo: discussões contemporâneas. 2.ed. Campinas: Papirus, 2007.

BARRETO, M. Relações entre Visitantes e Visitados: um retrospecto dos estudos Socioantropológicos. Turismo em Análise, v. 15, n. 2, p. 133-149, nov. 2004

BENI, M. C. Análise estrutural do turismo. 8.ed. São Paulo: SENAC, 2002. 523 p.

BOLEY, B. B.; MCGEHEE, N. G.; PERDUE, R. R.; LONG, P. Empowerment and resident attitudes toward tourism: Strengthening the theoretical foundation through a Weberian lens. Annals of Tourism Research, v. 49, p. 33-50, nov. 2014.

BOLEY, B. B.; STRZELECKA, M.; \& WOOSNAM, K. M. Resident perceptions of the economic benefits of tourism: Toward a common measure. Journal of Hospitality \& Tourism Research, v. 42, n. 8, p. 1295-1314, nov. 2018.

BRANDÃO, C. N.; BARBIERI, J. C.; REYES JÚNIOR, E. Análise dos impactos sociais, culturais, econômicos e ambientais do turismo indígena: estudo multicasos em comunidades indígenas de Roraima. In: Anais do XXXVII Encontro da Anpad, Rio de Janeiro, 1-16, 11, set. 2013.

CHAGAS, M. M. Avaliação dos impactos sócio-econômicos do turismo gerados pelo setor hoteleiro: uma análise dos hotéis da Via Costeira-Natal/RN. Revista Espaço Acadêmico, v. 13, n. 153, p. 93-104, fev. 2014.

CHAGAS, M. M.; SILVA, M. A.; SILVA, V. H.; MARQUES JÚNIOR, S. Classificação de residentes em relação ao apoio para o desenvolvimento de destinos turísticos costeiros. Anais do XII Seminário da Associação Brasileira de Pós-graduação em Turismo (ANPTUR), 2016.

DAMÁSIO, A. O Erro de Descartes: emoção, razão e o cérebro humano. São Paulo: Companhia das Letras. 1996.

DIAS, R. Introdução ao turismo. São Paulo: Atlas, 2005. 178 p. 
DOXEY, G. A Causation Theory of Visitor-Resident Irritants: Methodology and Research Inferences. The Impact of Tourism. In the Sixth Annual Conference Proceedings, pp.195-198. San Diego: The Travel Research Association. 1975.

ESTEVES, M. C. A sustentabilidade de empreendimentos rurais: um estudo a partir da implantação do turismo rural no estado de São Paulo. São Carlos: UFSCar. 2005.145 p.

FUNK, D.; JAMES, . Consumer loyalty: The meaning of attachment in the development of sport team allegiance. Journal of Sport Management, v. 20, n. 2, p. 189-217, 2006.

GARROD, B.; FYALL, A. Beyond the rhetoric of sustainable tourism? Tourism Management. Vol 19, no 3, pp: 199-212. jun.1998

GURSOY, D.; JUROWSKI, C.; UYSAL, M. Resident attitudes: a structural modeling approach. Annals of Tourism Research, v. 29, n. 1, p. 79-105, jan. 2002.

GURSOY, D.; RUTHERFORD, D. G. Host attitudes toward tourism: An improved structural model. Annals of Tourism Research, v. 31, n. 3, p. 495-516, jul. 2004.

HALLAL, D. R., \& MÜLLER, D. Impactos do turismo na cidade de Pelotas/RS, segundo a comunidade local. Revista Eletrônica de Administração e Turismo v. 3, n. 2, p. 269-279, jul. - dez. 2013.

HARALAMBOPOULOS, N.; PIZAM, A. Perceived impacts of tourism: The case of Samos. Annals of tourism Research, v. 23, n. 3, p. 503-526, jul. 1996.

HIDALGO, M. C.; HERNÁNDEZ, B. (2001). Place attachment: Conceptual and empirical questions. Journal of environmental psychology, v. 21, n. 3, p. 273-281, sep. 2001.

IBGE-Instituto Brasileiro de Geografia e Estatística. Disponível em: https://cidades.ibge.gov.br/brasil/rn /canguaretama/panorama. Acesso em: 20 jul. 2018.

JOO, D. et al.Residents' attitude towards domestic tourists explained by contact, emotional solidarity and social distance. Tourism Management, v. 64, p. 245-257, feb. 2018.

JUROWSKI, C.et al. A theoretical analysis of host community resident reactions to tourism. Journal of travel research, v. 36, n. 2, p. 3-11, nov. 1997.

KRIPPENDORF J. Sociologia do turismo: para uma compreensão do lazer e das viagens. 3. ed. São Paulo: Aleph, 2009. 237 p.

LIMA, D. M.; BOMFIM, Z. A. Vinculação afetiva pessoa-ambiente: diálogos na psicologia comunitária e psicologia ambiental. Psico, v. 40, n. 4, p. 11, 2009. 
LV Q, XIE X, LI Y. The Effects of Resident Empowerment on Intention to Participate in Financing: The Roles of Personal Economic Benefit and Negative Impacts of Tourism. Journal of China Tourism Research, v. 15, n. 4, p. 541-562, may. 2019.

MCGEHEE, N.; ANDERECK, K. Factors predicting rural residents' support of tourism. Journal of travel research, v. 43, n. 2, p. 131-140, nov. 2004.

MEHRABIAN, A.; RUSSELL, J.A. An approach to environmental psychology. the MIT Press, 1974.

NUNKOO, R.; RAMKISSOON, H.; GURSOY, D. Public trust in tourism institutions. Annals of Tourism Research, v. 39, n. 3, p. 1538-1564, jul. 2012.

PERDUE, R. R.; LONG, P. T.; ALLEN, L. Resident support for tourism development. Annals of tourism Research, v. 17, n. 4, p. 586-599, 1990.

PEREIRA, F. V. Percepções dos residentes sobre os impactos, satisfação com o lugar, governança e apoio ao desenvolvimento do turismo no Seridó Potiguar. 101f. Dissertação (Mestrado em Turismo) - Universidade Federal do Rio Grande do Norte, Natal, 2017.

RIBEIRO, M. A. et al. Tourists' destination loyalty through emotional solidarity with residents: An integrative moderated mediation model. Journal of Travel Research, v. 57, n. 3, p. 279-295, mar. 2018.

RICHINS, Marsha L. Measuring emotions in the consumption experience. Journal of consumer research, v. 24, n. 2, p. 127-146, sep. 1997.

RODRIGUES, A. P.; VIEIRA, I.; MARQUES, C. P.; TEIXEIRA, M. S. Apoio da comunidade residente ao desenvolvimento turístico sustentável: um modelo de equações estruturais aplicado a uma cidade histórica do Norte de Portugal. Tourism \& Management Studies, v. 10, n. 2, p. 17-25, jul. 2014.

ROLLERO, C.; DE PICCOLI, N. Place attachment, identification and environment perception: An empirical study. Journal of Environmental Psychology, v. 30, n. 2, p. 198-205, jun. 2010.

RODRIGUES, K. F.; RIPPEL, R. Desenvolvimento sustentável e técnicas de mensuração. Revista de Gestão Ambiental e Sustentabilidade. v. 4 n. 3, 73-88, set - dez. 2015

RODRIGUES, S. S. Turismo sustentável em destinos rurais - o papel dos residentes. 2012. Dissertação (Mestrado) - Curso de Gestão e Planejamento em Turismo, Universidade de Aveiro, Aveiro, 2012.

SANTORO, M. A. Análise da relação entre apego ao lugar, satisfação e fidelidade dos visitantes em destinos turísticos ambientais: um estudo em Fernando de Noronha/PE. 2014. 107 f. Dissertação (Mestrado em Turismo e Desenvolvimento Regional e Gestão em Turismo) - Universidade Federal do Rio 


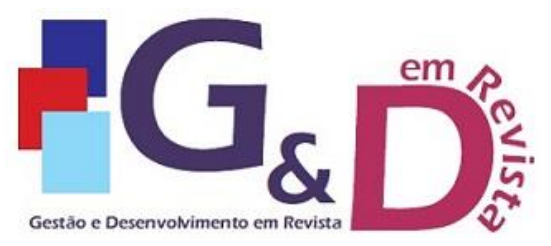

Gestão e Desenvolvimento em Revista V. 8, N. 2, jul-dez/2021, p. 153-169.

ISSN online: $2446-8738$

Artigo recebido em: 11/02/2021

Artigo aprovado em: 08/09/2021

Grande do Norte, Natal, 2014.

SCALABRINI, E.; REMAOLDO, P.; LOURENÇO, J. M. Perceções de residentes a respeito dos impactes da atividade turística: Uma análise das publicações brasileiras sobre o tema, Tourism and Hospitality International Journal, v. 2 n. 2, 12-31.mai. 2014

SILVA, V. H. Fatores que influenciam o apoio dos residentes ao desenvolvimento do turismo em destinos turísticos costeiros. 2018. 94f. Dissertação (Mestrado em Turismo) - Centro de Ciências Sociais Aplicadas, Universidade Federal do Rio Grande do Norte, Natal, 2018.

SILVA, V. H.; CHAGAS, M. Análise da relação entre perfil sociodemográfico da comunidade local e o grau de apoio ao desenvolvimento da atividade turística. Anais do XII Seminário da Associação Brasileira de Pós-graduação em Turismo (ANPTUR), 2016.

STYLIDIS, D.; BIRAN, A.; SIT, J.; SZIVAS, E. M. Residents' support for tourism development: The role of residents' place image and perceived tourism impacts. Tourism management, v. 45, p. 260-274, Dec. 2014.

TONON, L. M.; CARDOZO, P. EFETIVAÇÃO DO PLANEJAMENTO TURÍSTICO PARTICIPATIVO NAS POLÍTICAS PÚBLICAS DE TURISMO DO PARANÁ. Revista de investigación en turismo y desarrollo local. V. 6, n. 14, jun. 2013.

VIEIRA, K. Avaliação do apoio dos residentes no processo de gestão de projetos turísticos ambientais: um estudo do vale dos dinossauros -Sousa /PB. 2014.116f. Dissertação (Mestrado em Turismo). Universidade Federal do Rio Grande do Norte, Natal/RN, 2014.

WANG, S.; CHEN, J. S. The influence of place identity on perceived tourism impacts. Annals of Tourism Research, v. 52, p. 16-28, may. 2015.

WANG, Y.; PFISTER, R. E. Residents' attitudes toward tourism and perceived personal benefits in a rural community. Journal of Travel Research, v. 47, n. 1, p. 84-93, jan. 2008.

WARD, C.; BERNO, T. Beyond social exchange theory: Attitudes toward tourists. Annals of tourism research, v. 38, n. 4, p. 1556-1569, oct. 2011.

WATSON, D.; CLARK, L.A.; TELLEGEN, A. Development and validation of brief measures of positive and negative affect: the PANAS scales. Journal of personality and social psychology, v. 54, n. 6, p. 1063, jun. 1988.

WILLIAMS, D.R. et al. Beyond the commodity metaphor: Examining emotional and symbolic attachment to place. Leisure sciences, v. 14, n. 1, p. 29-46, jul. 1992.

WOOSNAM, K. M.; NORMAN, W. C. (2010). Measuring residents' emotional solidarity with tourists: Scale development of Durkheim's theoretical constructs. 

V. 8, N. 2, jul-dez/2021, p. 153-169. ISSN online: $2446-8738$

Journal of Travel Research,49, 365-380.

WOOSNAM, K. M. et al. Social determinants of place attachment at a World Heritage Site. Tourism Management, v. 67, p. 139-146, aug. 2018.

WOOSNAM, K. M..; ALESHINLOYE, K. D. Residents' emotional solidarity with tourists: Explaining perceived impacts of a cultural heritage festival. Journal of Hospitality \& Tourism Research, v. 42, n. 4, p. 587-605, apr. 2018.

XU, S. et al. Residents' perceptions of wine tourism development. Tourism Management, v. 55, p. 276-286, aug. 2016.

YU, C.; COLE, S. T.; CHANCELLOR, C.. Resident support for tourism development in rural midwestern (USA) communities: Perceived tourism impacts and community quality of life perspective. Sustainability, v. 10, n. 3, p. 802, jan. 2018.

1 ZACARIAS, Daniel Augusta. Turismo em áreas balneares: uma análise da interação entre residentes e visitantes na Praia do Tofo, Moçambique. Revista de Gestão Costeira Integrada, v. 15, n. 2, p. 179-1 